\title{
Design and multi-objective optimization for a broad self-amplified 2-DOF monolithic mechanism
}

\author{
THANH-PHONG DAO ${ }^{1,2}$ and SHYH-CHOUR HUANG ${ }^{3, *}$ \\ ${ }^{1}$ Division of Computational Mechatronics, Institute for Computational Science, Ton Duc Thang University, \\ Ho Chi Minh City, Vietnam \\ ${ }^{2}$ Faculty of Electrical \& Electronics Engineering, Ton Duc Thang University, Ho Chi Minh City, Vietnam \\ ${ }^{3}$ Department of Mechanical Engineering, National Kaohsiung University of Applied Sciences, Kaohsiung \\ 80778, Taiwan, ROC \\ e-mail: shuang@cc.kuas.edu.tw
}

MS received 28 March 2015; revised 31 May 2016; accepted 19 January 2017; published 1 September 2017

\begin{abstract}
This paper proposes a structural design and multi-objective optimization of a two-degree-of-freedom (DOF) monolithic mechanism. The mechanism is designed based on compliant mechanism with flexure hinge and is compact in size $(126 \mathrm{~mm}$ by $107 \mathrm{~mm})$. Unlike traditional one-lever mechanisms, a new doublelever mechanism is developed to increase the working travel amplification ratio of the monolithic mechanism. The ideal amplification ratio, the working travel, the statics and the dynamics of the mechanism are taken into consideration. The effects of design variables on the output responses such as the displacement and first natural frequency are investigated via finite-element analysis based on response surface methodology. The fuzzy-logicbased Taguchi method is then used to simultaneously optimize the displacement and the first natural frequency. Experimental validations are conducted to verify the optimal results, which are compared to those of the original design. On using a finite-element method, the validation results indicated that the displacement and frequency are enhanced by up to $12.47 \%$ and $33.27 \%$, respectively, over those of the original design. The experiment results are in a good agreement with the simulations. It also revealed that the developed fuzzy-logic-based Taguchi method is an effectively systematic reasoning approach for optimizing the multiple quality characteristics of compliant mechanisms. It was noted that the working travel/displacement of the double-lever mechanism is much larger than that of the traditional one-lever mechanism. It leads to the conclusion that the proposed mechanism has good performances for manipulations and positioning systems.
\end{abstract}

Keywords. Compliant mechanism; flexure hinge; monolithic mechanism; double-lever mechanism; working travel amplification ratio; response surface methodology; Taguchi method; fuzzy logic; multi-objective optimization.

\section{Introduction}

Two-degree-of-freedom (2-DOF) monolithic mechanisms are now widely used for high-precision positioning systems and manipulations. A 2-DOF monolithic mechanism is generally driven via piezoelectric actuator (PEA) to achieve higher resolution and faster motion, which is designed based on compliant mechanism with flexure hinges. Such mechanisms have garnered significant interest from both manufacturers and academic researchers [1-3]. The working travel/displacement amplification ratio is an important criterion for designing monolithic mechanisms [4-6]. In addition to the displacement amplification, the motion speed of the manipulations is also important in meeting the demand for rapid response [7]. Increasing the first natural

*For correspondence frequency results in a faster speed for the mechanism $[8,9]$. Most studies on 2-DOF monolithic mechanisms have used one-lever-type amplification mechanisms to enhance the working travel. Unlike the previous studies, this paper proposes a new double-lever-type mechanism to achieve a travel amplification ratio greater than that of conventional one-lever mechanisms.

As mentioned before, both the displacement and the first natural frequency need to be simultaneously taken into consideration. A large displacement and a high first natural frequency can be simultaneously obtained through a proper multi-objective optimization process. However, far too little attention has been paid to an optimization problem of both the displacement and the first natural frequency for the monolithic mechanisms.

The novelty of the present study is the use of a doublelever mechanism that allows a large travel amplification 
ratio, as well as simultaneous optimization of both the displacement and the first natural frequency.

This paper hence aimed to design a multi-objective optimization for a novel broad travel self-amplified 2-DOF monolithic mechanism. First, the ideal amplification ratio, the working travel, the statics and the dynamics of the mechanism are analysed. Then the fuzzy-logic-based Taguchi method is developed to simultaneously optimize the displacement and the first natural frequency. A prototype is then manufactured via wire electrical discharge machining process. Finally, experimental validations are carried out to verify the optimal results, which are then compared to those of the original design.

\section{Mechanical design}

Flexure hinges are significantly associated with the designing of 2-DOF monolithic mechanisms because of their simplified manufacture, absence of friction, lubricant and backlash, and high precision over traditional kinetic joints/bearing [10]. Flexure hinges with rectangular crosssections $[11,12]$ were adopted for the monolithic mechanism because they bend easily about one axis, and exhibit less stress concentration. The 2-DOF monolithic mechanism in this paper was designed to be compact in size (about $126 \mathrm{~mm}$ by $107 \mathrm{~mm}$ ), as shown in figure 1 .

As seen in figure $2 a$, the mechanism consists of the following members: (1) fixed hole, (2) flexure hinge, (3) platform, (4) double-lever mechanism and (5) PEA1 and PEA2. PEA1 was connected to the $\mathrm{E}$ point of the double-lever mechanism to increase the displacement of the platform in the $y$-axis. On the contrary, PEA2 was connected to the F point of the double-lever mechanism to increase the displacement of the platform in the $x$-axis. The double-lever mechanism

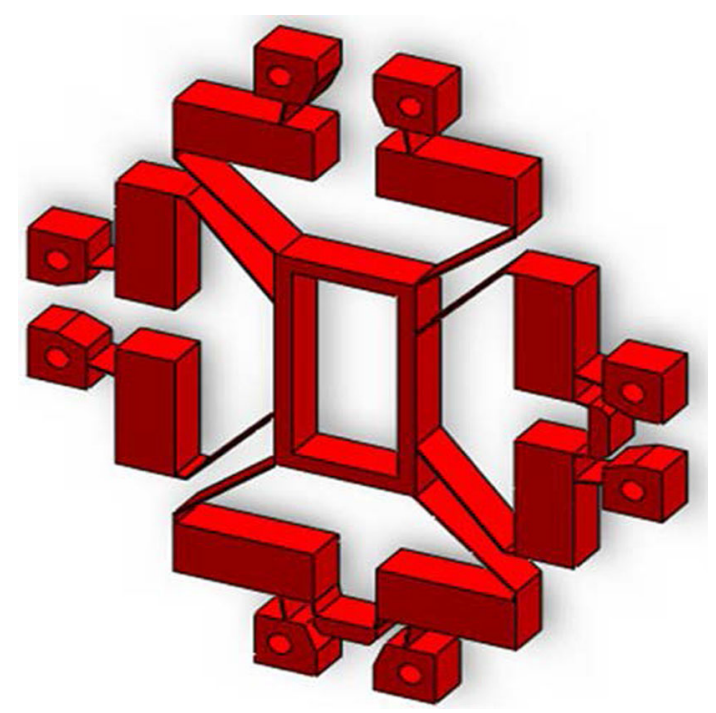

Figure 1. A 3-D model of the 2-DOF monolithic mechanism. included two single one-lever mechanisms connected together through the flexure hinges. Therefore, the travel amplification ratio of the proposed mechanism could be significantly increased. This leads to a broad self-amplified travel based on the double-lever mechanism. Al 7075-T73 material of 8-mm thickness was chosen for the mechanism because of its high yield strength-to-Young's modulus ratio and light relative density. The mechanical properties of Al 7075-T73 are as follows: Young's modulus $(E)$ is $72 \mathrm{GPa}$, yield strength $\left(\sigma_{y}\right)$ is $435 \mathrm{MPa}$, Poisson ratio (v) is 0.33 and density $(\rho)$ is $2810 \mathrm{~kg} / \mathrm{m}^{3}$. A magnified view of the double-lever mechanism with detailed design parameters is given in figure $2 \mathrm{~b}$. Table 1 gives the design parameters of the mechanism.

The monolithic mechanism was designed to provide a planar motion along the $x$ - and $y$-axis. When the mechanism displaced along the $x$-axis, the displacement/deflection of the mechanism along the $y$-axis also appeared at the same time. The displacement of the mechanism in the $y$-axis is called as a cross-axis coupling; this is an undesired motion because it causes a decrease in the positioning precision for the monolithic mechanism.

In general, a hinge would enable the compliance in the only DOF but the parasitic motion always exists in any flexure hinge. The parasitic motion is caused by flexure hinge's elastic deformation. In other words, the parasitic motion is

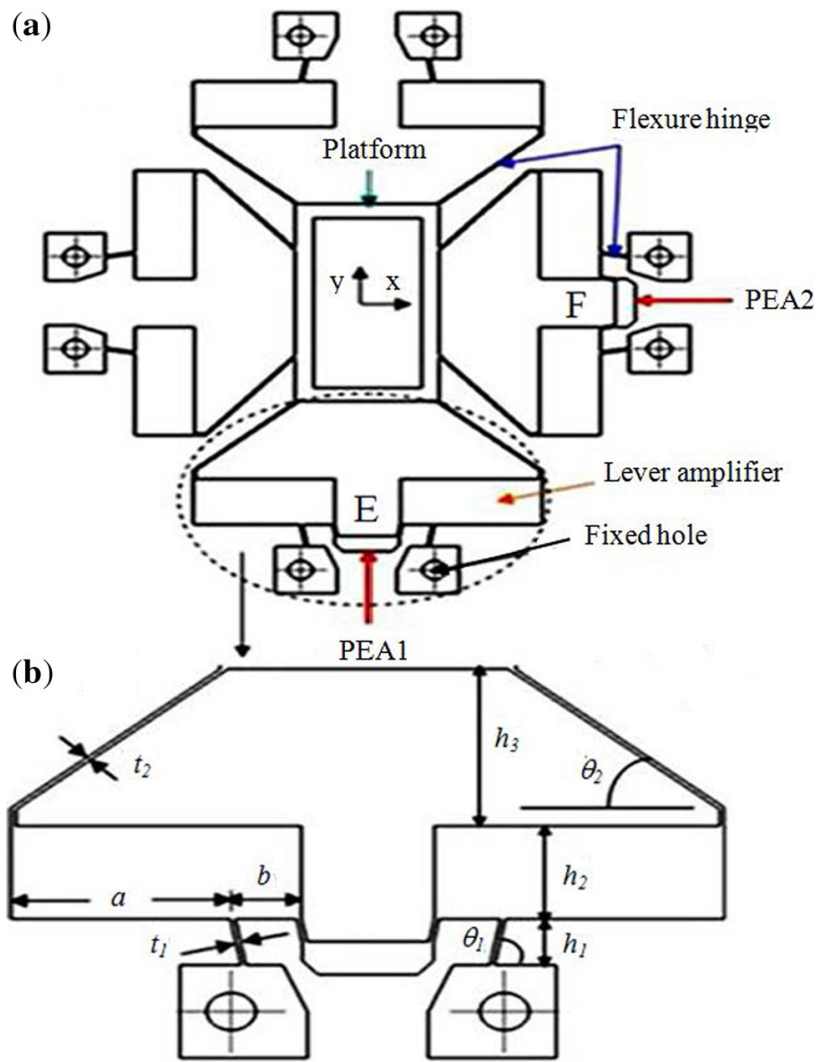

Figure 2. Detailed view: (a) a 2-D view of the mechanism and (b) a zoomed view of a mainframe with double levers. 
Table 1. Architecture parameters.

\begin{tabular}{lcc}
\hline Symbol & Value & Unit \\
\hline$t_{1}$ & $0.3 \leq t_{1} \leq 1$ & $\mathrm{~mm}$ \\
$t_{2}$ & $0.3 \leq t_{2} \leq 1$ & $\mathrm{~mm}$ \\
$A$ & 17.8 & $\mathrm{~mm}$ \\
$b$ & $4 \leq b \leq 7$ & $\mathrm{~mm}$ \\
$h_{1}$ & 4.92 & $\mathrm{~mm}$ \\
$h_{2}$ & 10 & $\mathrm{~mm}$ \\
$h_{3}$ & 16.82 & $\mathrm{~mm}$ \\
$\theta_{1}$ & 80 & $\mathrm{deg}$ \\
$\theta_{2}$ & 41.14 & $\mathrm{deg}$ \\
\hline
\end{tabular}

The total dimension of the 2-DOF mechanism is $126 \mathrm{~mm} \times 107 \mathrm{~mm} \times$ $8 \mathrm{~mm}$.

unavoidable. The cross-axis coupling is a result of the parasitic motion. If the cross-axis coupling is minimized, the positioning accuracy of the mechanism would be enhanced.

To decrease the coupling displacement between $x$ - and $y$ axis, a symmetric design of the double-lever mechanism in both axes is proposed in this study. Based on the symmetry, the mechanism nearly moved in the only DOF with minimized coupling displacement. The symmetry would restrict the coupling displacement. The cross-axis coupling would be clearly validated in section 4.6 .

The quality performances of the monolithic mechanism were assessed based on the displacement and first natural frequency. If the mechanism has a large displacement, the mechanism also has a large range of positioning that is suitable for different applications. In addition, if the mechanism has a high first natural frequency, the response of the mechanism is faster. In reality, the flexure hinges strength influences the performances of the mechanism. Hence, to achieve a large displacement and a high frequency, the design parameters of flexure hinges should be optimized. As the flexure hinges inside the mechanism have a symmetric structure, the two responding performances were optimized when PEA1 was applied only in the $y$-axis. In other words, the optimization process could be also performed with respect the PEA2 in the $x$-axis.

\section{Kinematic studies}

\subsection{Amplification ratio}

The working travel amplification is one of the most important factors for designing a compliant mechanism. In theory, the ideal travel amplification ratio of a lever amplification mechanism $r_{t}$ is calculated as follows:

$$
r_{t}=\frac{a}{b}
$$

where $r_{t}$ is the ideal travel amplification ratio of a lever amplification mechanism.
The actual travel amplification ratio of lever type mechanism $r_{a}$ can be calculated as the ratio of the output travel to the input travel, as shown in the following equation:

$$
r_{a}=\frac{o}{i}
$$

where $r_{a}$ is the actual travel amplification ratio, $i$ denotes the input travel of the platform and $o$ denotes the output travel of the platform.

In this study, a double-lever mechanism was developed to amplify the travel range of the monolithic mechanism. With such a double-lever mechanism, the amplification ratio of this type $r_{a}$ can be much larger than the computed amplification ratio $r_{t}$.

\subsection{Ideal kinematic relationships}

In the kinematic analysis, the mechanism is considered as a series of rigid bars linked by ideal revolute joints. In this analysis, the output travel of the platform is directly related to the motion of the lever mechanism and the input PEA travel. The displacements of the platform in the $x$ - and $y$-direction were computed in two cases, including the theoretical displacement and the actual displacement.

Theoretical displacements were calculated by the following equations:

$$
\begin{aligned}
& x_{o t}=r_{t} \times x_{i} \\
& y_{o t}=r_{t} \times y_{i}
\end{aligned}
$$

The actual displacements were determined as follows:

$$
\begin{aligned}
& x_{o a}=r_{a} \times x_{i} \\
& y_{o a}=r_{a} \times y_{i}
\end{aligned}
$$

where $x_{o t}$ and $y_{o t}$ are the theoretical displacement of the platform along the $x$ - and $y$-axis, respectively; $x_{o a}$ and $y_{o a}$ are the real displacements; $x_{i}$ is the input displacement of PEA2 along the $x$-axis, and $y_{i}$ is the input displacement of PEA1 along the $y$-axis.

\section{Computational analyses}

The finite-element method (FEM)-based computation analysis has been widely employed for design testing. It was used to investigate the displacement, the first natural frequency and the stress concentration in this study.

All analyses in this section were carried out via a finiteelement analysis (FEA) using ANSYS 13 software. A solid model with thicknesses $t_{1}=0.3 \mathrm{~mm}, t_{2}=0.4 \mathrm{~mm}$ and the thickness of each lever of $h_{1}=10 \mathrm{~mm}, a=17.8 \mathrm{~mm}$ and $b=5 \mathrm{~mm}$ was constructed for the monolithic mechanism. 

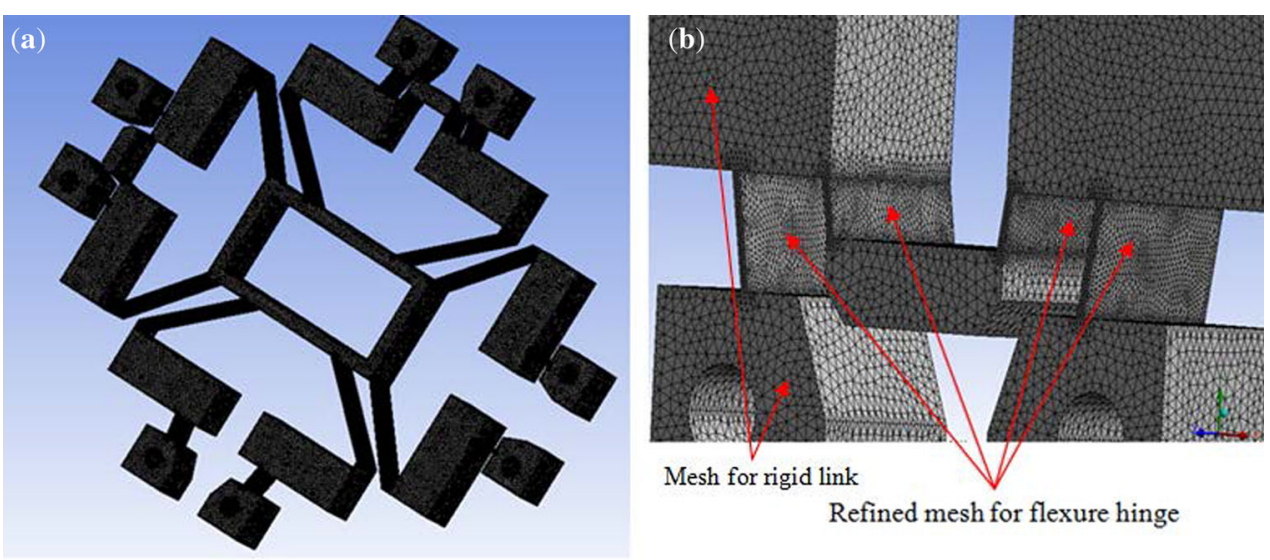

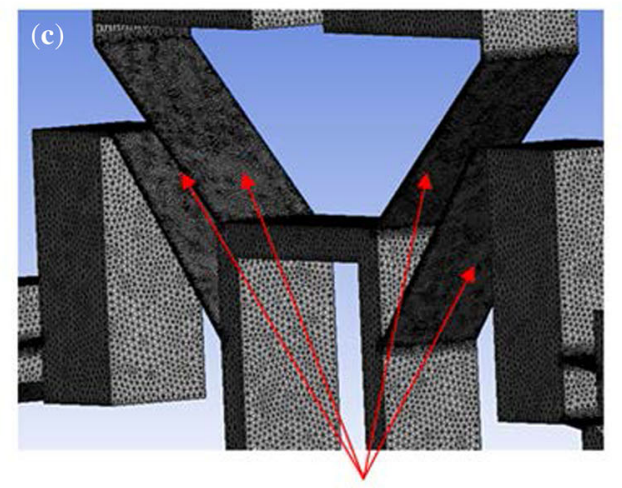

Refined mesh for flexure hinge

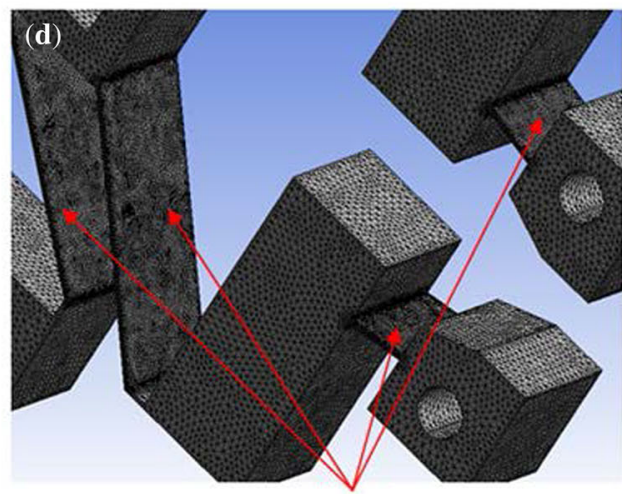

Refined mesh for flexure hinge

Figure 3. Meshed model: (a) model and (b)-(d) refinement mesh for flexure hinges.

The solid model of the mechanism was constructed in Solidworks and then imported into ANSYS. The automatic method of meshing was applied for the model. A 10-node tetrahedral structural solid element of SOLID 92 type was adopted for the meshed model because SOLID 92 is well suited for irregular meshes. The skewness criterion [13] was applied to evaluate the element quality. The number of elements was 898947 and the number of nodes was 1522354. A coarse meshing method was adopted in regions with smaller deformations of rigid links while all flexure hinges were refine meshed again through the refinement method to achieve better analysis results. The meshed model of the mechanism is depicted in figure 3a. The results indicate that all flexure hinges have a mesh much better than that of rigid links, as shown in figure $3 \mathrm{~b}-\mathrm{d}$. Regarding the actual boundary conditions as in practice, the immobile parts were fixed as holes in figure $2 \mathrm{a}$. The platform moves along the $y$-axis when PEA1 is applied to the $\mathrm{E}$ point, as depicted in figure 2a. In another case, the platform is translated along the $x$-axis when the PEA2 is applied to the $\mathrm{F}$ point, as shown in figure $2 \mathrm{a}$.

\subsection{Travel amplification ratio}

The double-lever mechanism was used to amplify the travel range of the mechanism instead of the traditional one-lever mechanism. The double-lever mechanism included two levers that were assigned in a symmetric structure. The middle point of the double-lever mechanism was regarded as an input loading location with PEA. Compared with the one-lever mechanism, the double-lever mechanism can have a larger travel amplification ratio and this would be proven by FEA.

A model of one-lever mechanism and a model of double-lever mechanism are constructed in Solidworks, as seen in figure $4 \mathrm{a}$ and $\mathrm{b}$, respectively. To validate this point of view, these two models were analysed by FEA in ANSYS. The two models had the same boundary conditions. The fixed holes were considered to have zero displacement. For the purpose of comparison, the one-lever mechanism and the double-lever mechanism were subjected to the input of PEA1. Different values of PEA1, 10, $15,20,25$ and $30 \mu \mathrm{m}$, were used to drive the two models, individually. The displacements of two models along the $y$-axis were recorded.

The output displacements of one-lever mechanism and double-lever mechanism were defined as $d_{1}$ and $d_{2}$, respectively. The $d_{2} / d_{1}$ ratios were calculated. As given in table 2, the output displacement of double-lever mechanism was much larger than that of one-lever mechanism. Besides, the travel amplification ratio of one-lever mechanism (calculated ratio around 2.8) was 
(a)

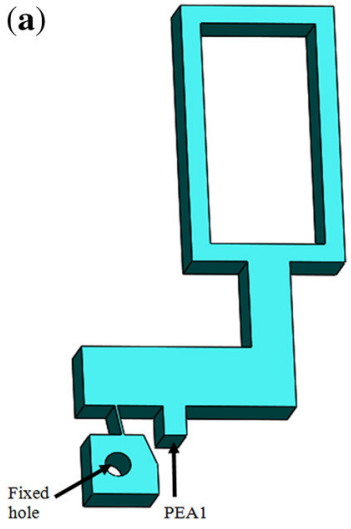

(b)

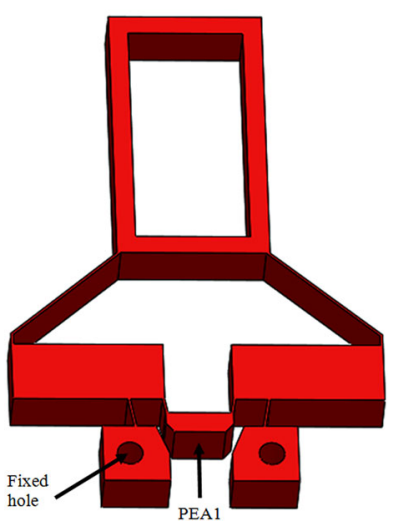

Figure 4. Model of amplification types: (a) one-lever mechanism and (b) double-lever mechanism.

Table 2. Displacements and displacement ratios of two-lever amplification types.

\begin{tabular}{cccc}
\hline & \multicolumn{2}{c}{ Output displacement $(\mu \mathrm{m})$} & \\
\cline { 2 - 3 } $\begin{array}{c}\text { PEA1 } \\
(\mu \mathrm{m})\end{array}$ & $\begin{array}{c}\text { One-lever } \\
\text { mechanism }\left(d_{1}\right)\end{array}$ & $\begin{array}{c}\text { Double-lever } \\
\text { mechanism }\left(d_{2}\right)\end{array}$ & $\begin{array}{c}\text { Displacement } \\
\text { ratio }\left(d_{2} / d_{1}\right)\end{array}$ \\
\hline 10 & 28 & 60 & 2.14 \\
15 & 43 & 90 & 2.09 \\
20 & 57 & 120 & 2.10 \\
25 & 71 & 150 & 2.11 \\
30 & 86 & 178 & 2.06 \\
\hline
\end{tabular}

much lower than that of double-lever mechanism (calculated ratio about 6.0). In addition, the $d_{2} / d_{1}$ displacement ratios were greater than 2.0. It implies that the displacement of double-lever mechanism is over twice greater than that of one-lever mechanism. To this end, the double-lever mechanism was adopted as an effective travel amplification mechanism in designing the 2-DOF monolithic mechanism.

As mentioned before, the amplification ratio of this type $r_{a}$ could be much larger than the computed amplification ratio $r_{t}$. To prove this hypothesis, assume that length $a$ is $17.8 \mathrm{~mm}$, and length $b$ is $5 \mathrm{~mm}$; then the amplification ratio $r_{t}$ is 3.56 . Figure 5 shows that when the input values of PEA1 along the $y$-axis are 10,15, 20, 25 and $30 \mu \mathrm{m}$, the travel of the platform is 58.1, 87.1, 116.2, 145.2 and $174.2 \mu \mathrm{m}$, respectively. As a result, the actual amplification ratio $r_{a}$ is approximately 5.81, which is much larger than the $r_{t}$ of 3.56. The same analysis for the $x$-axis, as shown in figure 6 , reveals that when the input values of PEA2 are $10,15,20,25$ and $30 \mu \mathrm{m}$, the travel of the platform is $63.2,94.9,126.5,158.2$ and $189.8 \mu \mathrm{m}$, respectively. The actual amplification ratio $r_{a}$ is thus approximately 6.3 , which is much larger than the $r_{t}$ of 3.56 .

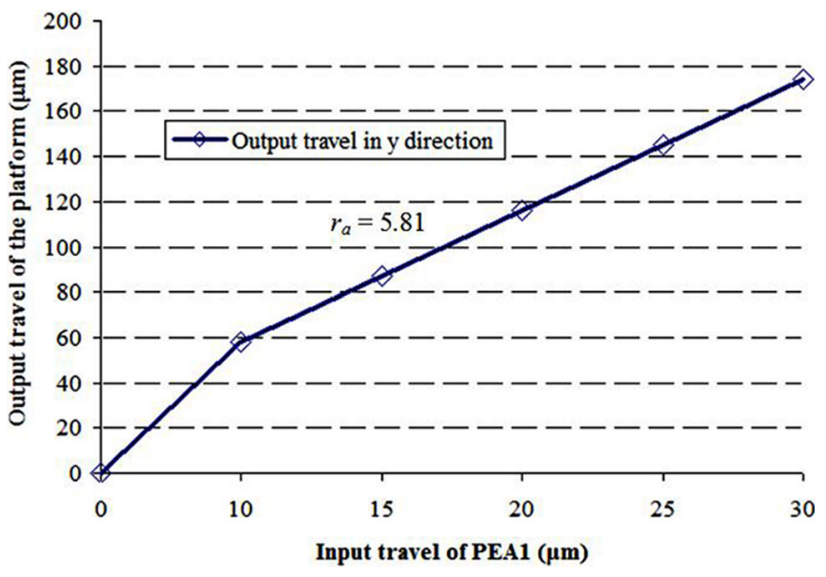

Figure 5. Diagram of the output displacement versus PEA1 input.

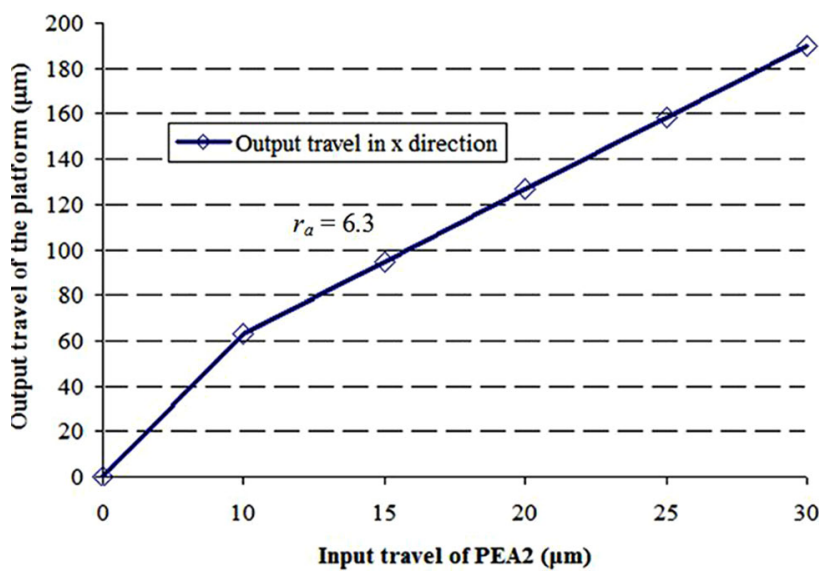

Figure 6. Diagram of the output displacement versus PEA2 input.

\subsection{Working travel}

The displacement of the mobile platform is defined as the working travel of the mechanism. When the input displacements of PEA1 were 10,15, 20, 25 and $30 \mu \mathrm{m}$ applied to the E point, the corresponding output displacement of the platform in the $y$-direction was recorded. As shown in figure 7, the real output displacement of the platform was much higher than the theoretical one of the platform. It was noted that the displacement of the platform was improved by up to $38.7 \%$ compared with the theoretical displacement.

When the input displacements of PEA2 were 10, 15, 20, 25 and $30 \mu \mathrm{m}$ applied to the $\mathrm{F}$ point, the corresponding output displacement of the platform in the $x$-direction was recorded. As shown in figure 8 , it is clear that the real output displacement of the platform is much higher than the theoretical one of the platform. It could be concluded that the displacement of the platform was improved by up to $43.67 \%$ compared with the theoretical displacement. 


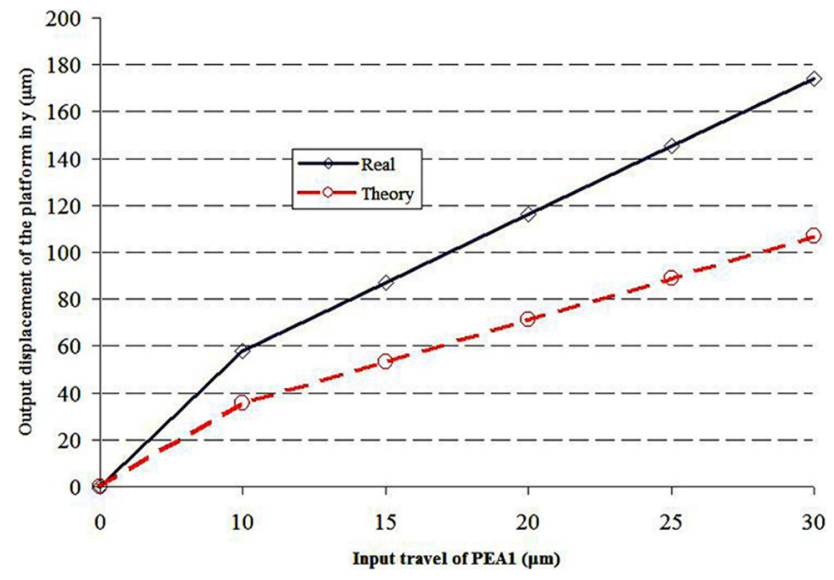

Figure 7. Comparison between the theoretical displacement and the real displacement in the $y$-direction.

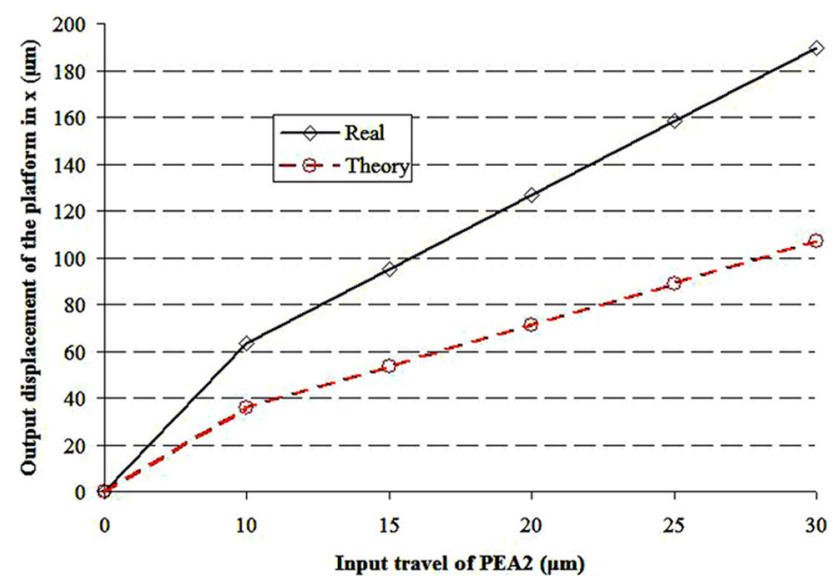

Figure 8. Comparison between the theoretical displacement and the real displacement.

\subsection{Analysis of stress distribution}

In the proposed 2-DOF compliant mechanism, the maximum equivalent von Mises stress was determined in order to guarantee longevity of the mechanism. An input displacement PEA1 of $30 \mu \mathrm{m}$ was applied along the $y$-axis to investigate the maximum stress that the mechanism would encounter.

Similarly, PEA2 value of $30 \mu \mathrm{m}$ was employed along the $x$-axis to test for maximum stress. When PEA1 was applied, the maximum stress was $70.173 \mathrm{MPa}$, and in other positions the corresponding stresses were 15.51, 36.05 and 39.20 $\mathrm{MPa}$, as seen in figure 9. When PEA2 was applied, the maximum stress was $62.95 \mathrm{MPa}$, and in other positions the corresponding stresses were 15.03, 35.03 and $38.19 \mathrm{MPa}$, as shown in figure 10. Both stress values are well below the yield strength of the material (435 MPa), which guarantees the mechanism's durability and longevity.

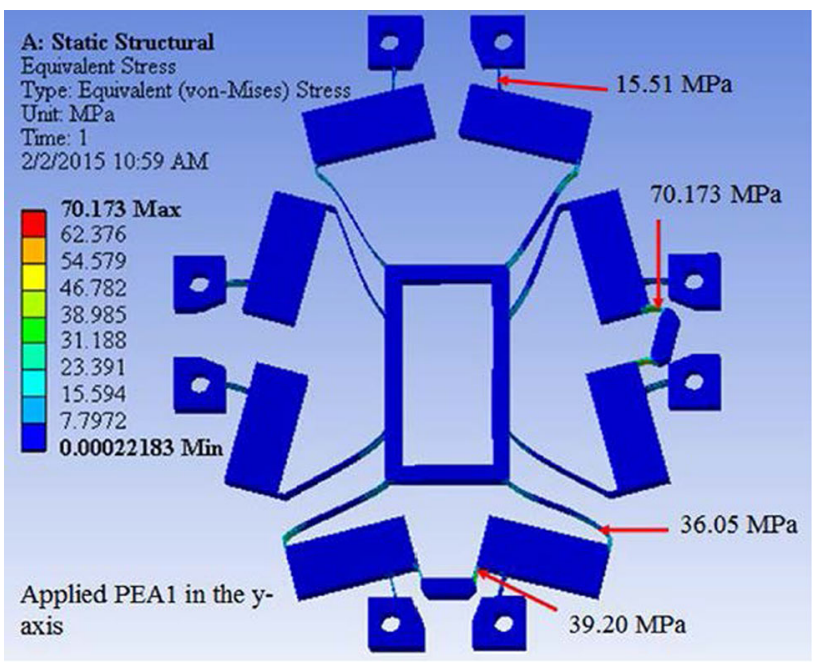

Figure 9. Stress distribution when PEA1 was applied.

When both PEA1 and PEA2 of $30 \mu \mathrm{m}$ were activated simultaneously, the stress distributions were determined using ANSYS. As depicted in figure 11, the maximum stress was $142.09 \mathrm{MPa}$, and in other positions the corresponding stresses were 110.52 and $78.94 \mathrm{MPa}$ followed by 63.15 MPa. These stresses were much less than the yield strength of the material (435 MPa). It can be concluded that the mechanism can operate well with a long fatigue life, a highly sufficient safety and guaranteed long-term performance of the mechanism.

\subsection{Analysis of vibration modes}

In manipulations and positioning systems, the natural first frequencies and corresponding mode shapes are primary factors affecting the response speed of the mechanism. The modal FEA simulation was conducted to evaluate the dynamic performance of the developed mechanism.

In reality, the PEA is considered as a spring with a constant stiffness; one end of the spring is directly in contact with the mechanism and the other end is fixed. Prior to operation, a screw is usually used to generate a preload on the PEA. The purpose of preload to the PEA is to establish good contact with the mechanism. However, the stiffness of the mechanism can be increased by adding the stiffness of the PEA and the preload. As a result, the PEA1 directly affects the natural frequency of the mechanism. Hence, two case studies with the PEA1 and without PEA1 were taken into consideration.

For the study discussed in this section, the model was designed with thickness $t_{1}=0.3 \mathrm{~mm}, t_{2}=0.4 \mathrm{~mm}$ and the thickness of each lever was $h_{1}=10 \mathrm{~mm}, a=17.8 \mathrm{~mm}$ and $b=5 \mathrm{~mm}$. Later an FEA was performed using ANSYS. The meshing automatic method was also used and the 10-node 


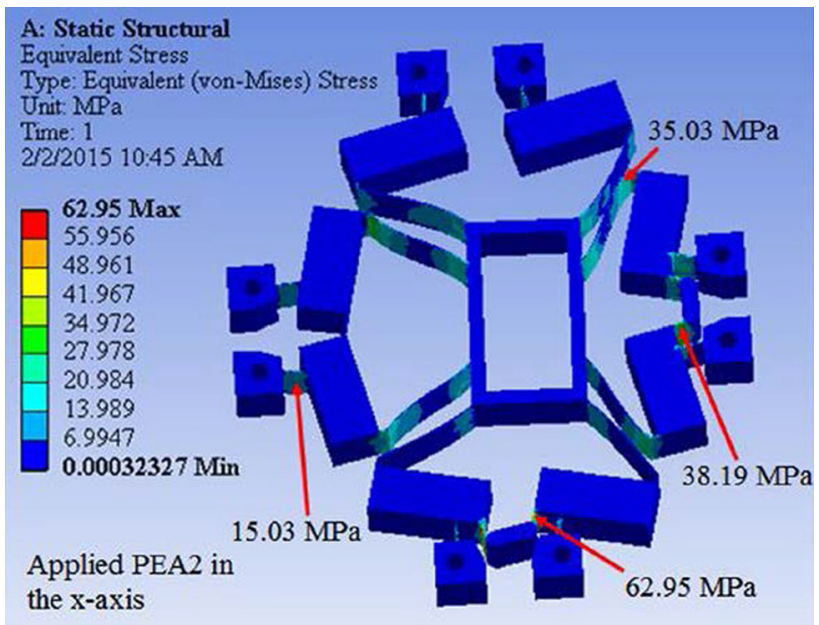

Figure 10. Stress distribution when PEA2 was applied.

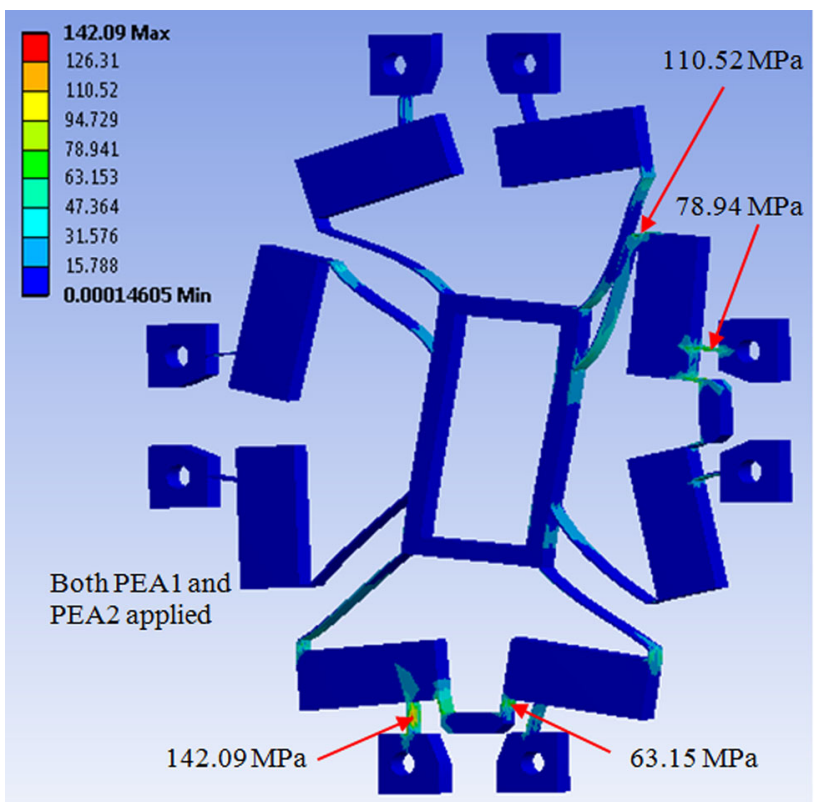

Figure 11. Stress distribution when both PEA1 and PEA2 were applied simultaneously.

tetrahedral structural solid element of SOLID 92 was adopted for the model. Al 7075-T73 was used for the FEA model. The boundary conditions of the FEA model are identical to the actual boundary conditions, where the immotile parts are constrained by zero displacements. The parts of zero displacements were the eight fixed holes, as shown in figure $2 \mathrm{a}$. The mobile parts included the rigid links and flexure hinges. The rigid links were meshed by a coarse meshing method, while the flexure hinges were refined again by the refinement method to obtain good analysis results. The modal analysis was conducted to extract the eight mode shapes and corresponding natural frequencies of the mechanism.

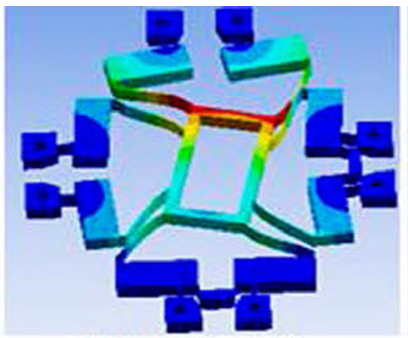

(1 $397.41 \mathrm{~Hz}$

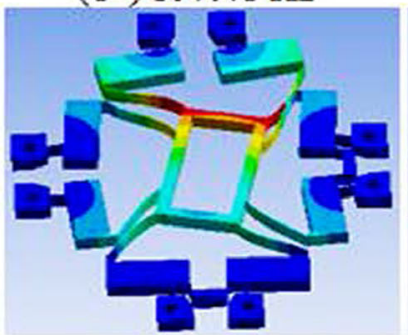

(3:d) $1034.3 \mathrm{~Hz}$

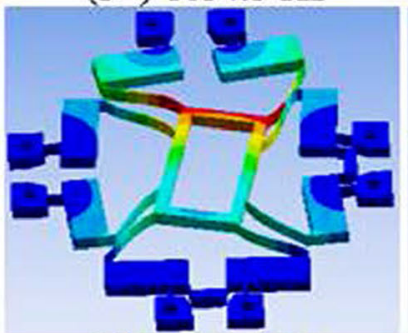

(5 $\left.5^{\text {th }}\right) 1352.4 \mathrm{~Hz}$

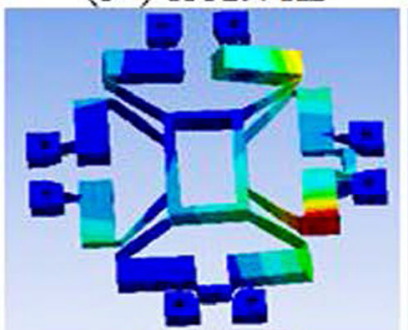

(7h) $1987.6 \mathrm{~Hz}$

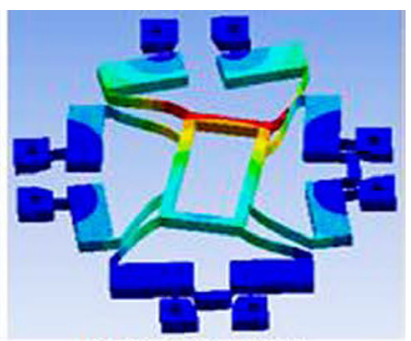

(2nd) $991.65 \mathrm{~Hz}$

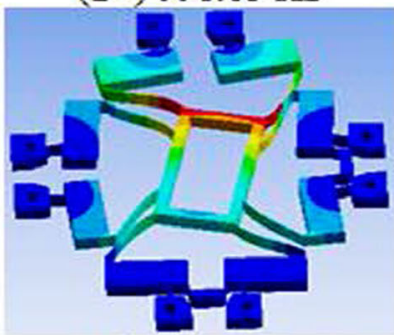

(4th) $1202.0 \mathrm{~Hz}$

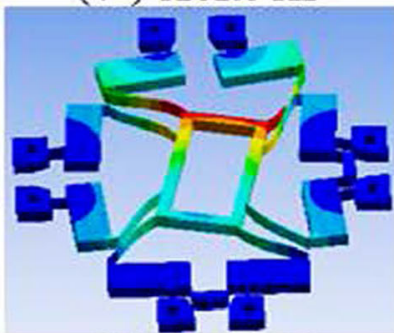

(6 $\left.6^{\text {th }}\right) 1534.8 \mathrm{~Hz}$

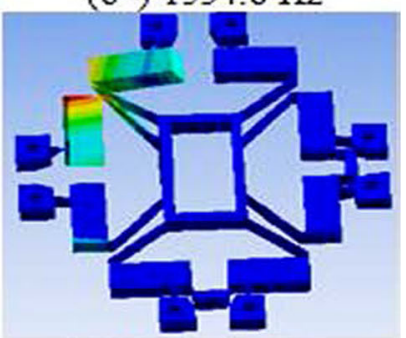

( $\left.8^{\text {th }}\right) 2153.5 \mathrm{~Hz}$
Figure 12. Mode shapes of the mechanism with PEA1.

First, the 30- $\mu \mathrm{m}$ PEA1was applied to E point (see figure $2 \mathrm{a}$ ) and the platform was moved. The platform was designed for planar motion; thus, the modes within the $x$ $y$ plane are the most significant. As shown in figure 12, the first six modes represent the rotational motion about the $z$ axis. The seventh and eighth modes correspond to the local out-of-plane modes of the levers. With the applied PEA1, the eight mode shapes and the corresponding natural frequencies are shown in figure 12. The values of the corresponding natural frequencies are 397.41, 991.65, 1034.3, 1203.0, 1352.4, 1534.8, 1987.6 and $2153.5 \mathrm{~Hz}$. It was noted that the first natural frequency of $397.41 \mathrm{~Hz}$ was relatively high. Hence, the responding speed of the monolithic mechanism was also improved faster and it was able to accelerate manipulation and positioning systems of the mechanism. 
Table 3. Natural frequencies of the mechanism.

\begin{tabular}{lcc}
\hline Mode shapes & With PEA1 $(\mathrm{Hz})$ & Without PEA1 $(\mathrm{Hz})$ \\
\hline $1^{\text {st }}$ & 397.41 & 248.22 \\
$2^{\text {nd }}$ & 991.65 & 251.68 \\
$3^{\text {rd }}$ & 1034.30 & 251.68 \\
$4^{\text {th }}$ & 1203.00 & 491.51 \\
$5^{\text {th }}$ & 1352.40 & 989.07 \\
$6^{\text {th }}$ & 1534.80 & 1197.60 \\
$7^{\text {th }}$ & 1987.60 & 1259.30 \\
$8^{\text {th }}$ & 2153.50 & 1852.10 \\
\hline
\end{tabular}

Table 4. Coded levels of the design variables.

\begin{tabular}{lllllll}
\hline & & \multicolumn{5}{c}{ Coded levels } \\
\cline { 3 - 7 } Factors & Unit & -2 & \multicolumn{1}{c}{-1} & \multicolumn{1}{c}{0} & \multicolumn{1}{c}{1} & 2 \\
\hline$t_{1}$ & $\mathrm{~mm}$ & 0.3 & 0.475 & 0.65 & 0.825 & 1 \\
$t_{2}$ & $\mathrm{~mm}$ & 0.3 & 0.475 & 0.65 & 0.825 & 1 \\
$b$ & $\mathrm{~mm}$ & 4 & 4.75 & 5.5 & 6.25 & 7 \\
\hline
\end{tabular}

Finally, the modal analysis of the mechanism without the PEA1 was carried. The results show that the corresponding natural frequencies are as follows: 248.22, 251.68, 251.68, 491.51, 989.07, 1197.6, 1259.3, 1852.1 and $2151.1 \mathrm{~Hz}$. Without the PEA1, the first, second and third modes represent the motion in the $x-y$ plane. The remaining modes represent the out-of-plane motion at local lever components. As presented in table 3, the frequencies of the mechanism without PEA1 were lower than those with PEA1. It is clear that the PEA1 can significantly improve the natural frequencies of the developed mechanism.

\subsection{Effect of design variables on responses}

Prior to the optimization, the effects of the three design variables (input parameters) on displacement and frequency (output parameters) were a critical problem. The response surface methodology [14] is a statistic technique, which is widely used for an optimization process.

In this paper, FEA based on the response surface methodology [13] was used as a statistical regression model to illustrate the relationships between the input design parameters and output performances. First, a model of the 2-DOF mechanism was created in the design modeller module using ANSYS. Second, the three input parameters and the two output parameters were made parametric variables. In this step, the thickness $t_{1}$ was established at $0.3-1 \mathrm{~mm}$; the thickness $t_{2}$ was established at $0.3-1 \mathrm{~mm}$ and the length $b$ was established at 4-7 $\mathrm{mm}$. Third, the design points were generated automatically using the central composite design method. In this step, each level of each input parameter was automatically generated. Finally,

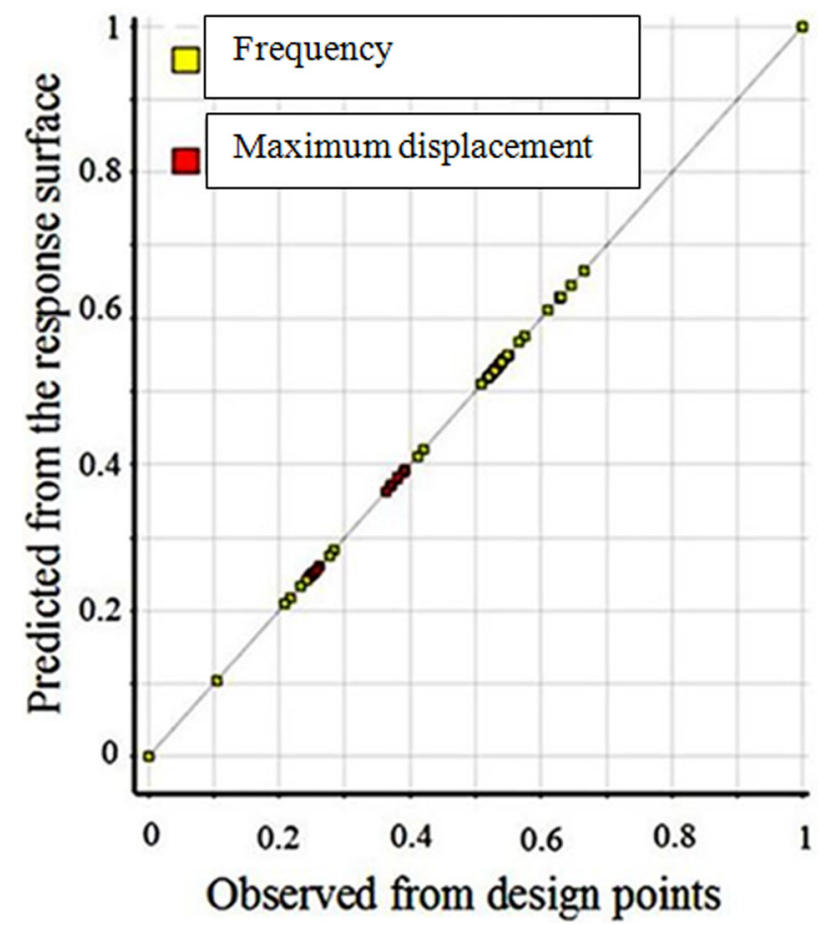

Figure 13. Goodness of fit of the response surfaces and the design points.

based on the design points, a response surface was created. As a result, the effects of the three design variables on displacement and frequency were achieved.

To illustrate this relationship on the same plot, each level of each parameter was coded to be similar. The coded levels for the design variables are given in table 4; the effects of the design variables on the two output parameters are considered, and shown in only one figure. Figure 13 shows goodness of fit of the response surfaces and the design points. As seen in figure $14 \mathrm{a}$ and $\mathrm{b}$, displacement and frequency varied when each of the three design variables was changed, respectively. Based on the computational analysis from figure 14, all the three design variables showed a direct influence on displacement and frequency. Thus, all three parameters were considered for the optimization problem.

\subsection{Analysis of cross-axis coupling}

The cross-axis coupling is an undesired parasitic displacement for any positioning mechanism because it reduces the positioning accuracy. This study evaluates the correlation between the displacement along the $y$-axis and the cross-axis coupling motion along the $x$-axis via FEA through ANSYS.

To perform this analysis, assume that only PEA1 with different values $(5,10,15,20,25$ and $30 \mu \mathrm{m})$ is activated and thus the mechanism moved. The displacement along the $y$-axis and cross-axis coupling along the $x$-axis were determined. The ratio $(\%)$ of the cross-axis coupling $\left(c_{x}\right)$ to 


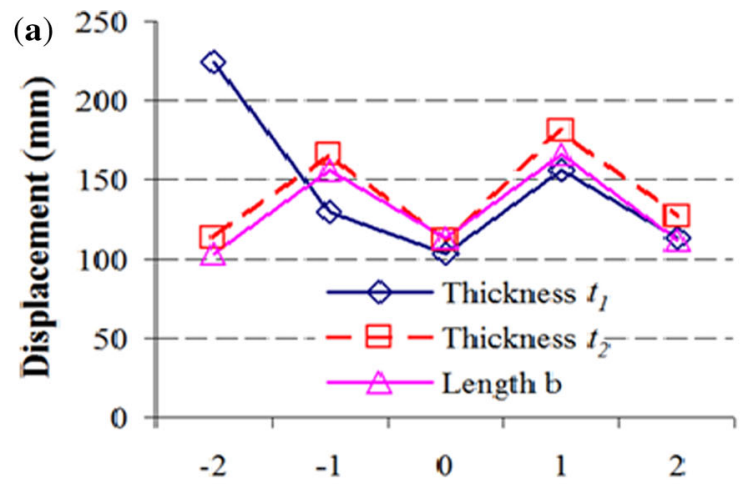

Coded levels

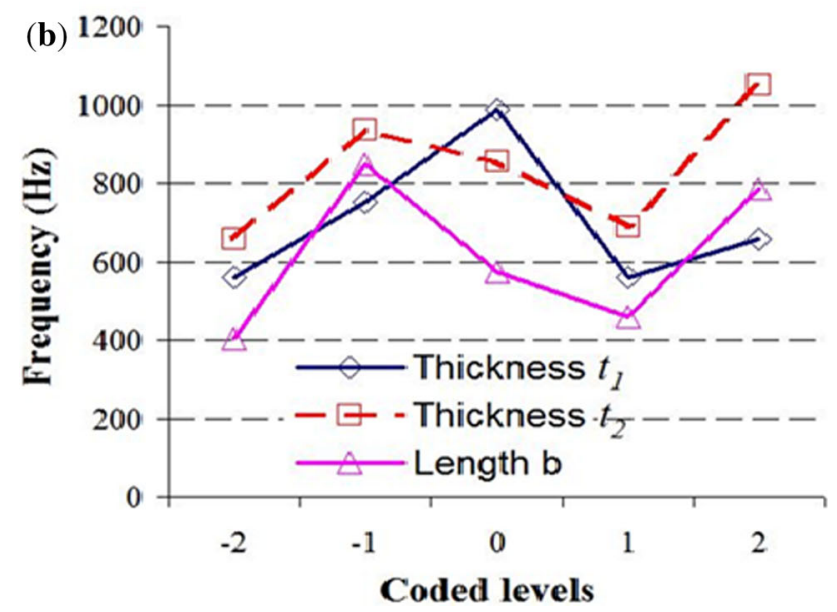

Figure 14. Influence plots: (a) displacement and (b) frequency.

Table 5. Displacement $\left(d_{y}\right)$, cross-axis coupling $\left(c_{x}\right)$ and ratio of $c_{x} / d_{y}$.

\begin{tabular}{rccc}
\hline $\begin{array}{l}\text { PEA1 } \\
(\mu \mathrm{m})\end{array}$ & $\begin{array}{c}\text { Displacement along } \\
\text { the } y \text {-axis }\left(d_{y}\right)\end{array}$ & $\begin{array}{c}\text { Cross-axis coupling } \\
\text { along the } x \text {-axis }\left(c_{x}\right)\end{array}$ & $\begin{array}{c}c_{x} / d_{y} \\
\text { ratio } \\
(\%)\end{array}$ \\
\hline 5 & 28.98 & 0.06 & 0.20 \\
10 & 57.96 & 0.13 & 0.22 \\
15 & 86.95 & 0.20 & 0.23 \\
20 & 115.93 & 0.27 & 0.23 \\
25 & 144.92 & 0.34 & 0.23 \\
30 & 173.90 & 0.41 & 0.23 \\
\hline
\end{tabular}

the displacement $\left(d_{y}\right)$ was calculated. The results show that these ratios are less than $2.4 \%$, as given in table 5. It can be concluded that the mechanism is capable of translating along the $y$-axis well with a very small cross-axis coupling.

\section{Multi-objective optimization}

\subsection{Optimization problem formulation}

The displacement and the first natural frequency are the two most important criteria in positioning and manipulation. If the platform has a large displacement, then it will have a broad positioning capacity; if the platform has a high first natural frequency, it can response rapidly. Thus, the displacement and the first natural frequency should be simultaneously optimized. The double-lever mechanism was created with a symmetric structural design with respect to the $x$ - and $y$-axis; therefore, the PEA1 of $30 \mu \mathrm{m}$ was applied only to the E point of double-lever mechanism so that the mechanism would move along the $y$-axis. The multi-objective optimization problem is described as follows.

$$
\text { Find } t_{1}, t_{2} \text { and } b
$$

maximize the displacement (DI)

maximize the first mode of natural frequency (FR)

subject to constraints:

$$
\begin{gathered}
r_{a} \geq 5 \\
\sigma \leq \frac{\sigma_{y}}{S F} \\
0.3 \mathrm{~mm} \leq t_{1} \leq 1 \mathrm{~mm} \\
0.3 \mathrm{~mm} \leq t_{2} \leq 1 \mathrm{~mm} \\
4 \mathrm{~mm} \leq b \leq 7 \mathrm{~mm}
\end{gathered}
$$

where SF is the safety factor, selected as 2.5 . This factor was proposed to guarantee a high safety for the mechanism during its operation. The safety factor is generally made as large as possible, so that flexible mechanisms can deflect/ displace without failure, such as plastic failure or fatiguedecreased life.

In order to create greater motion, the resistance of the flexure hinges must be reduced, which requires decreasing the thickness of the flexure hinges, regardless of whether they have circular or rectangular geometries. The design optimization therefore focuses on finding the optimal thicknesses. Moreover, according to the theory of compliant mechanisms, the maximum stress of the flexure hinges is mainly dependent on their thickness. Equation (15) shows that the thickness $t$ has a critical effect on the maximum stress [4]:

$$
\sigma_{\max }=\frac{6 M_{z} K_{t}}{t^{2} w}
$$

where $\sigma_{\max }$ is the maximum equivalent stress, $M_{z}$ is the axis movement, $K_{t}$ is the stress concentration factor, $t$ is the thickness variable of the flexure hinges and $w$ is the thickness of the proposed mechanism, called the constant width of the flexure hinges $(w=8 \mathrm{~mm})$.

In this work, if the thickness was much lower than $0.3 \mathrm{~mm}$, it was impossible for the wire electrical discharge machine to fabricate the mechanism with a tolerance of 


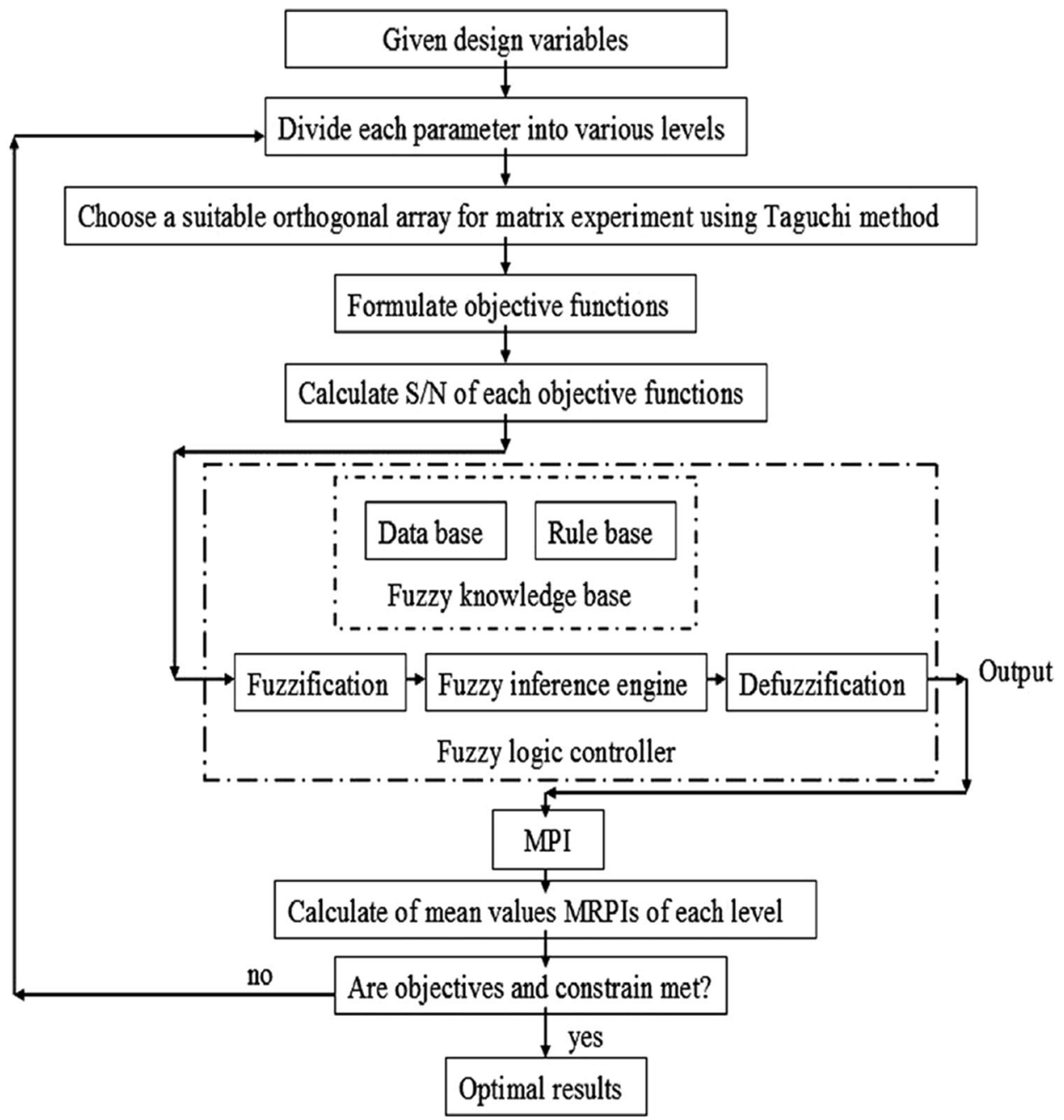

Figure 15. A flowchart of the fuzzy-logic-based Taguchi method.

Table 6. Parameters and levels.

\begin{tabular}{lcccccc}
\hline Symbol & Parameter & Range & Unit & $\begin{array}{c}\text { Level } \\
\text { Level }\end{array}$ & $\begin{array}{c}\text { Level } \\
2\end{array}$ & 3 \\
\hline$A$ & $\begin{array}{c}\text { Thickness } \\
t_{1}\end{array}$ & $0.3-1.0$ & $\mathrm{~mm}$ & 0.3 & 0.65 & 1.0 \\
& $\begin{array}{c}\text { Thickness } \\
t_{2}\end{array}$ & $0.3-1.0$ & $\mathrm{~mm}$ & 0.3 & 0.65 & 1.0 \\
& Length $b$ & $4.0-7.0$ & $\mathrm{~mm}$ & 4.0 & 5.5 & 7.0 \\
\hline
\end{tabular}

$\pm 0.01 \mathrm{~mm}$. However, if the thickness was much larger than $1 \mathrm{~mm}$, the mass of the stage could be increased and the proposed mechanism could become stiffer; as a result, the travel range would be decreased. The lower bounds for the parameters were selected to guarantee compliance. The upper bounds of the geometric dimensions were set to achieve a compact structure. In addition, if the distance $b$ was more than $7 \mathrm{~mm}$, the travel amplification ratio was reduced; if $b$ was less than $4 \mathrm{~mm}$, the mechanism was not safe at the hinges.
Table 7. Experimental plan $L_{9}$ orthogonal array.

\begin{tabular}{cccc}
\hline & \multicolumn{3}{c}{ Design parameters } \\
\cline { 2 - 4 } Trial no. & $t_{1}(\mathrm{~mm})$ & $t_{2}(\mathrm{~mm})$ & $b(\mathrm{~mm})$ \\
\hline 1 & 0.30 & 0.30 & 4.00 \\
2 & 0.30 & 0.65 & 5.50 \\
3 & 0.30 & 1.00 & 7.00 \\
4 & 0.65 & 0.30 & 5.50 \\
5 & 0.65 & 0.65 & 7.00 \\
6 & 0.65 & 1.00 & 4.00 \\
7 & 1.00 & 0.30 & 7.00 \\
8 & 1.00 & 0.65 & 4.00 \\
9 & 1.00 & 1.00 & 5.50 \\
\hline
\end{tabular}

\subsection{Optimal methodology}

The Taguchi method and fuzzy logic were coupled together to the multi-objective optimization problem in this paper. The Taguchi method has been used in a wide variety of engineering fields [15]. The Taguchi method is a statistical 
Table 8. Experimental results and their $S / N$ ratios.

\begin{tabular}{cccccc}
\hline $\begin{array}{l}\text { Trial } \\
\text { no. }\end{array}$ & $\begin{array}{c}\text { DI } \\
(\mathrm{mm})\end{array}$ & $\begin{array}{c}S / N \text { ratio of DI } \\
(\mathrm{dB})\end{array}$ & $\begin{array}{c}\text { FR } \\
(\mathrm{Hz})\end{array}$ & $\begin{array}{c}S / N \text { ratio of } \\
\text { FR }(\mathrm{dB})\end{array}$ & MPI \\
\hline 1 & 224.56 & 47.03 & 263.28 & 48.41 & 0.50 \\
2 & 129.97 & 42.28 & 749.70 & 57.50 & 0.54 \\
3 & 103.17 & 40.27 & 987.87 & 59.89 & 0.50 \\
4 & 155.73 & 43.85 & 303.01 & 49.63 & 0.25 \\
5 & 112.93 & 41.06 & 658.60 & 56.37 & 0.27 \\
6 & 165.97 & 44.40 & 935.24 & 59.42 & 0.75 \\
7 & 112.11 & 40.99 & 391.79 & 51.86 & 0.24 \\
8 & 181.17 & 45.16 & 689.73 & 56.77 & 0.61 \\
9 & 126.65 & 42.05 & 1051.80 & 60.44 & 0.63 \\
\hline
\end{tabular}

Table 9. Fuzzy rules.

\begin{tabular}{lcccc}
\hline & & \multicolumn{3}{c}{$S / N$ ratio of FR } \\
\cline { 3 - 5 } MPI & & Small & Middle & Large \\
\hline S/N ratio of DI & Small & Very small & Small & Middle \\
& Middle & Small & Middle & Large \\
& Large & Middle & Large & Very large \\
\hline
\end{tabular}

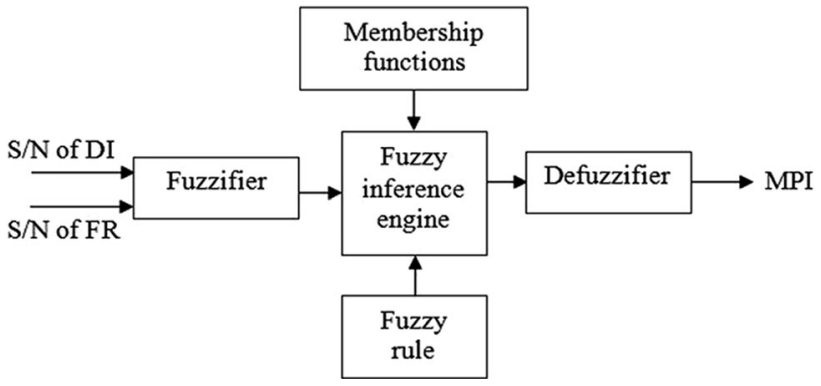

Figure 16. Fuzzy logic system.

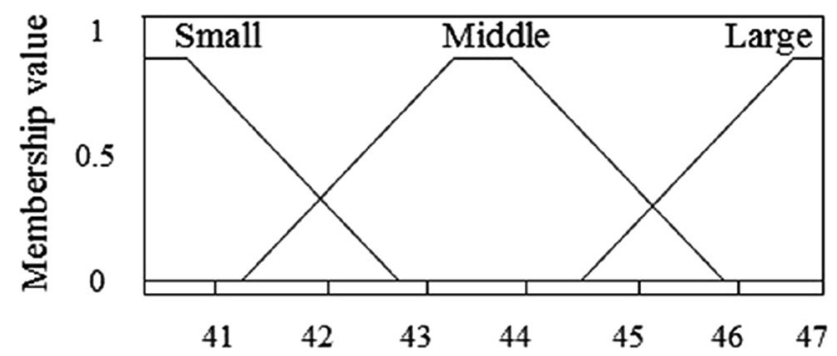

Figure 17. Membership function of $S / N$ ratio of DI.

method that is used to optimize a process of engineering experimentation and to solve robust design problems. It was initially used in experimental design by Dr. Genichi Taguchi, an electronic and communication engineer. The robust-parameter design is a useful method to optimize process parameters in order to achieve low variations and to minimize manufacturing costs.

Regarding the key tools, the Taguchi method uses an orthogonal array (OA) and the $S / N$ ratio. The OA, an especially constructed table, is used for selecting the best combinations of factor levels to lay out an experimental matrix. Regarding the OA matrix, the numbers are arranged in rows and columns where each column represents a specific factor and each row expresses the factor level in each experimental run. In the Taguchi method, an OA is a fractional factorial matrix that ensures a balanced combination of levels of any factor or interaction of factors. An $\mathrm{OA}$ is aimed to reduce the number of experiments instead of using a full factorial design.

The Taguchi method deals with statistical and sensitivity analysis in determining the optimum setting of parameters and achieving robust quality response. The response at the setting of parameters is considered as a measure that is not only the mean of quality performance but also its variance. The mean and variance will be then integrated into a single performance measure, which is known as the signal-tonoise $(S / N)$ ratio. The Taguchi method recommends the idea of using the $S / N$ ratio to evaluate the quality characteristics deviating from desired values. The $S / N$ ratio concept is an effective performance indicator to obtain improved quality performances by reducing variability. The Taguchi robust parameter design is based on the desired quality characteristics; the $S / N$ ratio can be categorized into three types as follows: the smaller-the-better, the higherthe-better and the nominal-is-the best.

In this study, the displacement (DI) and the first mode of the natural frequency (FR) were the two objective functions that required the maximum values. Hence, the higher-thebetter $S / N$ ratio was selected for two objectives.

The $S / N$ for higher-the-better is defined as

$$
\eta=-10 \log _{10}\left(\frac{1}{n}\right) \sum_{i=1}^{n} \frac{1}{y_{i}^{2}}
$$

where $n$ is the number of repeated experiments and $y_{i}$ is observed data in the $i^{\text {th }}$ experiment.

However, the Taguchi method can optimize for DI or FR only individually. This means that the Taguchi approach fails to perform the required simultaneous optimization for both DI and FR. To overcome this shortcoming, the Taguchi method was integrated with fuzzy logic. The proposed fuzzy-logic-based Taguchi method is an effective systematic reasoning approach for optimizing the multiple quality characteristics.

Using the fuzzy-logic-based Taguchi method, the optimization of multiple performance characteristics can be transformed into the optimization of a single performance index. Fuzzy logic is defined as a mathematical theory of inexact reasoning to describe uncertain information.

The basic structure of a fuzzy logic unit includes a fuzzifier, membership functions (MFs), a fuzzy rule 


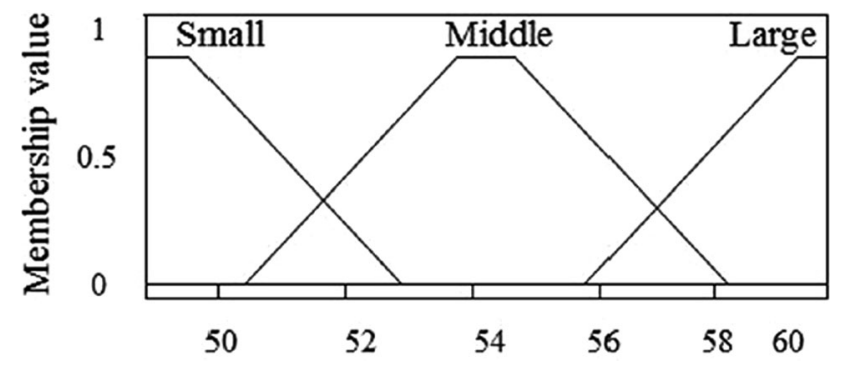

Figure 18. Membership function of $S / N$ ratio of FR.

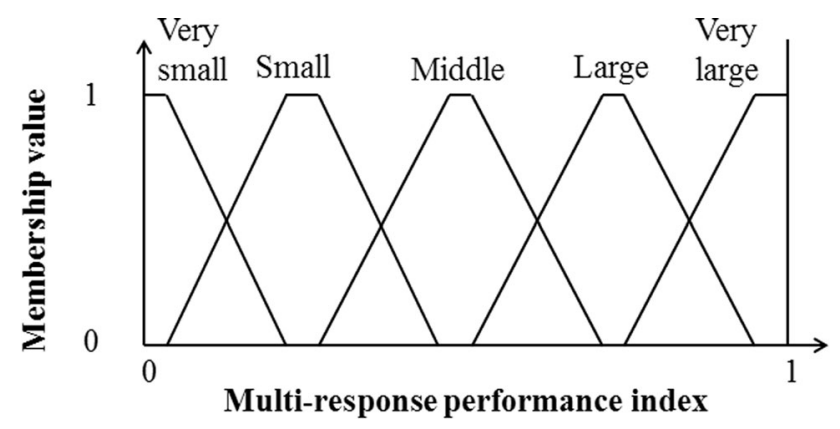

Figure 19. Membership function of MPI.

Table 10. Mean of MPI index at each level.

\begin{tabular}{lccc}
\hline & \multicolumn{3}{c}{ MPI } \\
\cline { 2 - 4 } Input parameter & Level 1 & Level 2 & Level 3 \\
\hline$A\left(t_{1}\right)$ & 0.51 & 0.42 & 0.49 \\
$B\left(t_{2}\right)$ & 0.33 & 0.47 & 0.63 \\
$C(b)$ & 0.62 & 0.47 & 0.34 \\
\hline
\end{tabular}

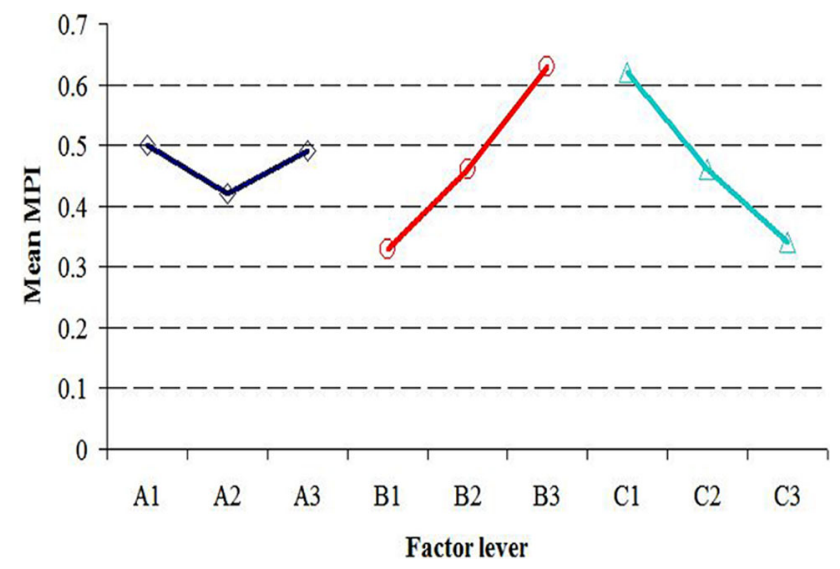

Figure 20. Response diagram of $S / N$ ratio (dB) at each level.

base, an inference engine and a defuzzifier. The principles of a fuzzy logic system are as follows: (1) the fuzzier employs the MFs to fuzzify the given input parameters, (2) the inference engine generates fuzzy
Table 11. Comparison of the original design with optimal design by FEM.

\begin{tabular}{|c|c|c|c|c|}
\hline Responses & Unit & $\begin{array}{l}\text { Original } \\
\text { design } \\
\text { A2B2C2 }\end{array}$ & $\begin{array}{l}\text { Optimal } \\
\text { design } \\
\text { A1B3C1 }\end{array}$ & $\begin{array}{c}\text { Improvement } \\
(\%)\end{array}$ \\
\hline Displacement & $\mu \mathrm{m}$ & 145.49 & 163.63 & 12.47 \\
\hline $\begin{array}{l}\text { First natural } \\
\text { frequency } \\
\text { (applied PEA1) }\end{array}$ & $\mathrm{Hz}$ & 653.95 & 871.53 & 33.27 \\
\hline
\end{tabular}

values via fuzzy rules based on fuzzy reasoning and the defuzzifier converts the fuzzy values into crisp output values.

This paper uses the $S / N$ ratio value of the displacement and the $S / N$ ratio value of the first natural frequency as the input variables for the fuzzy inference rules. Next, the trapezoidal MF is applied for fuzzification in order to achieve fuzzy sets. The fuzzy rules are then created in the inference engine to conduct fuzzy reasoning and obtain fuzzy values. Finally, the trapezoidal MF is applied for defuzzification in order to obtain a multiresponse performance index (MPI). In this study, the fuzzy input variables used trapezoidal functions as fuzzy logic MFs, and this MF type was applied to the output variable MPI. The trapezoidal MF is considered as a curve that determines how each point in the input space is mapped to a membership value (or degree of membership) between 0 and 1 . In this paper, each input was assigned three fuzzy subsets and each output established five subsets.

The equation of trapezoidal MFs is described as [Wierman, 16]

$$
\mu_{A}(x, a, l, r, b)=\left\{\begin{array}{cc}
\frac{(x-a)}{(l-a)} & \mathrm{a} \leq x \leq l \\
1 & l<x<r \\
\frac{(x-b)}{(r-b)} & r \leq x \leq b
\end{array}\right.
$$

where $\mu_{A}$ is the MFs of the fuzzy set; $a, b, l$ and $r$ are parameters and $x$ is a variable. The output variable MPI has five trapezoidal MFs in the fuzzy subsets, including very small, small, medium, large and very large.

The fuzzy rule base consists of a group of if-then control rules with two inputs: $x_{1}\left(S / N\right.$ ratio of DI) and $x_{2}(S / N$ ratio of FR), and one output $y$ (called MPI), as follows:

Rule 1 : if $x_{1}$ is $\mathrm{A}_{1}$ and $x_{2}$ is $\mathrm{B}_{1}$, then $y$ is $\mathrm{C}_{1}$ else Rule 2: If $x_{1}$ is $\mathrm{A}_{2}$ and $x_{2}$ is $\mathrm{B}_{2}$, then $y$ is $\mathrm{C}_{2}$ else

Rule 9: if $x_{1}$ is $\mathrm{A}_{9}$ and $x_{2}$ is $\mathrm{B}_{9}$, then $y$ is $\mathrm{C}_{9}$, 


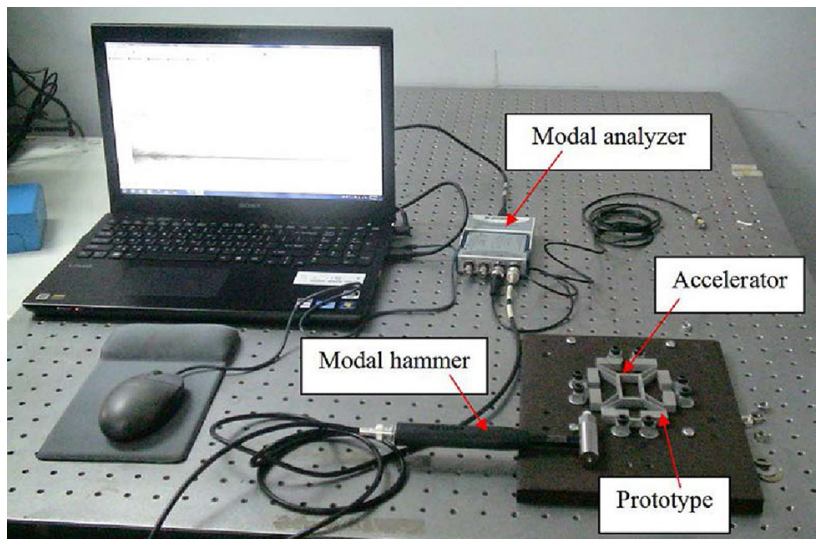

Figure 21. Photo of the experimental set-up for measurement of frequency response.

where $\mathrm{A}_{i}, \mathrm{~B}_{i}$ and $\mathrm{C}_{i}$ are fuzzy sets modelled using MFs $\mu_{A}$, $\mu_{B}$ and $\mu_{C}$, respectively, while $x_{1}$ and $x_{2}$ are the input variables and $y$ is the output variable.

The Mamdani implication method (a max-min composition operation) was used for this study, and the fuzzy reasoning of these rules then achieved a fuzzy output. The MF of the output of the fuzzy reasoning can be described as [17]

$$
\mu_{C_{0}}(y)=\left(\mu_{A_{1}}\left(x_{1}\right) \wedge \mu_{B_{1}}\left(x_{2}\right)\right) \vee \cdots \vee\left(\mu_{A_{9}}\left(x_{1}\right) \wedge \mu_{B_{9}}\left(x_{2}\right)\right)
$$

where $\wedge$ is the minimum operation and $\vee$ is the maximum operation.
Table 12. Comparison of the results of fist natural frequency without PEA1.

\begin{tabular}{|c|c|c|c|c|}
\hline Responses & Unit & $\begin{array}{l}\text { Optimal } \\
\text { design from } \\
\text { FEM } \\
\text { A1B3C1 }\end{array}$ & $\begin{array}{l}\text { Optimal design } \\
\text { from } \\
\text { experiments } \\
\text { A1B3C1 }\end{array}$ & $\begin{array}{c}\text { Error } \\
(\%)\end{array}$ \\
\hline $\begin{array}{l}\text { First natural } \\
\text { frequency } \\
\text { (without PEA1) }\end{array}$ & $\mathrm{Hz}$ & 498.27 & 476.00 & 4.67 \\
\hline
\end{tabular}

Finally, the fuzzy output is converted into an absolute value using the defuzzification method. In this study, the centre of gravity method for defuzzification is used to transform the fuzzy inference output $\mu_{C_{0}}(y)$ into a nonfuzzy value $y_{0}$ (called the MPI). MPI is then used to search for the optimal parameters. The value of MPI lies within the range of $0-1$. These steps were carried out using the Mamdani method in MATLAB ${ }^{\circledR} \mathrm{R} 20011 \mathrm{~b}$ [18] to transform the fuzzy inference output into a non-fuzzy value, i.e., the MPI value. The non-fuzzy value (or the final crisp output value $\left.y_{0} / \mathrm{MPI}\right)$ is calculated as [17]

$$
\text { MPI }=\frac{\sum y \mu_{C_{0}}(y)}{\sum \mu_{C_{0}}(y)}
$$

Regarding optimization of multiple quality characteristics, the traditional approaches such as genetic algorithm, particle swarm optimization, cuckoo search algorithm,

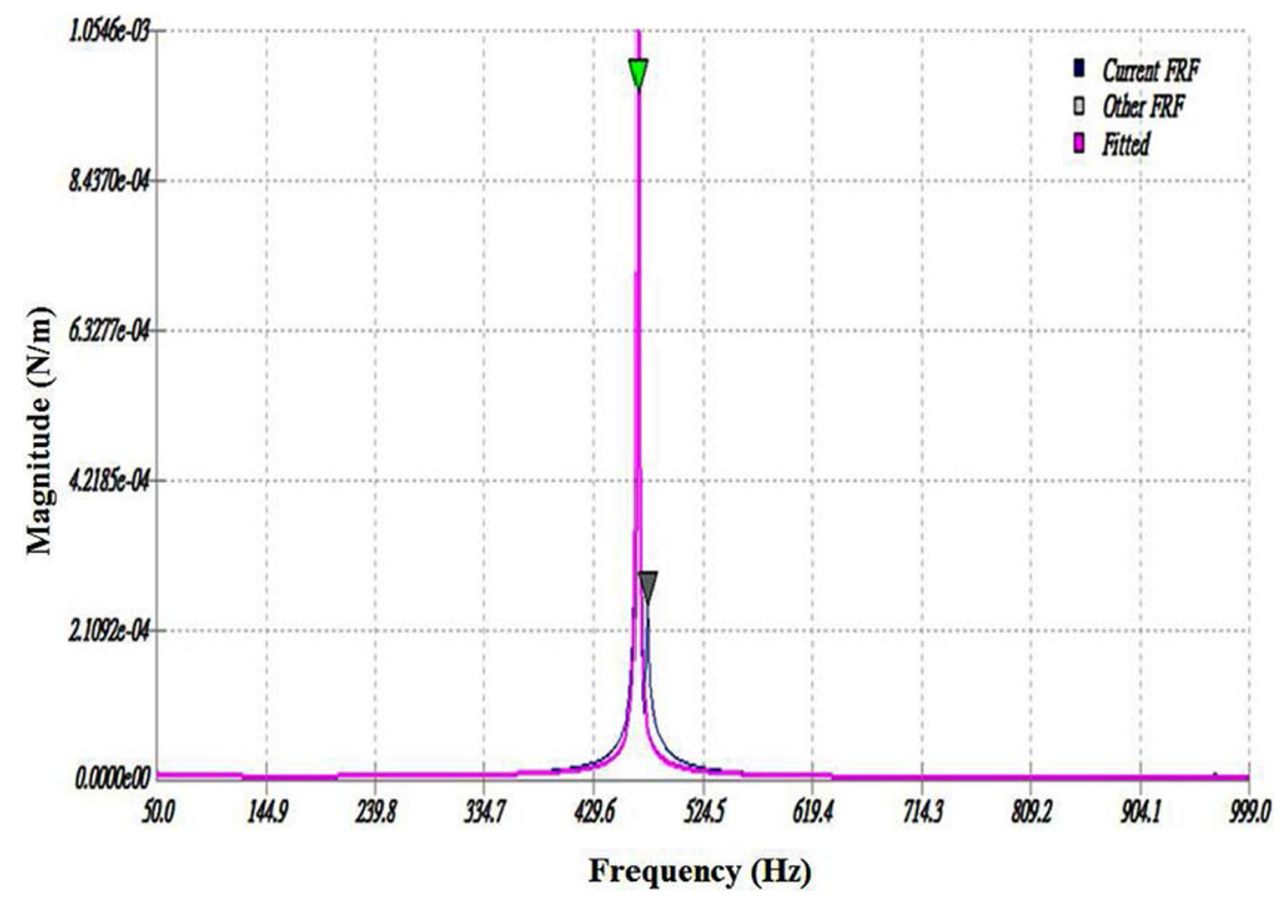

Figure 22. Diagram of the first natural frequency when the hammer excitation is in the $y$-axis. 


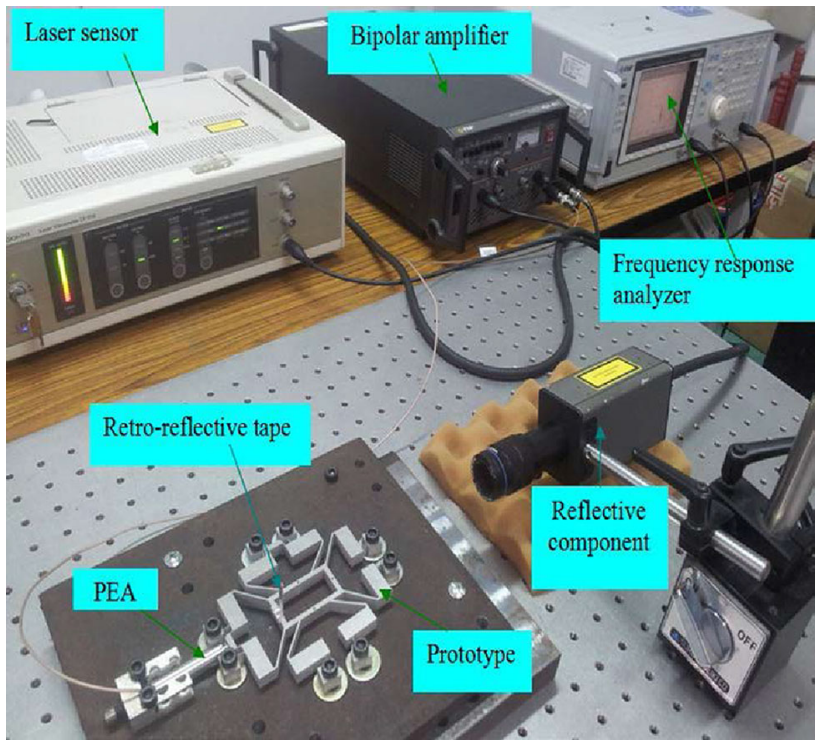

Figure 23. Photo of experiment set-up for displacement.

Table 13. Comparison of the FEM displacement and experimental displacement.

\begin{tabular}{|c|c|c|c|c|c|}
\hline Responses & Unit & $\begin{array}{l}\text { Optimal } \\
\text { design } \\
\text { A1B3C1 }\end{array}$ & $\begin{array}{l}\text { Optimal } \\
\text { design } \\
\text { from } \\
\text { FEM } \\
\text { A1B3C1 }\end{array}$ & $\begin{array}{c}\text { Optimal } \\
\text { design from } \\
\text { experiments } \\
\text { A1B3C1 }\end{array}$ & $\begin{array}{c}\text { Error } \\
(\%)\end{array}$ \\
\hline Displacement & $\mu \mathrm{m}$ & & 163.63 & 161.66 & 1.21 \\
\hline $\begin{array}{l}\text { Travel } \\
\text { amplification } \\
\text { ratio }\end{array}$ & & 4.45 & 5.45 & 5.39 & 1.11 \\
\hline
\end{tabular}

evolution differential algorithm were used to determine the weight for each output response. The weight was generally based on the experience of the engineer and scientists, which introduced many uncertainties. In this present study, the fuzzy-logic-based Taguchi method, which used MPI, reduced human uncertainties and thus complex mathematical computations were not required.

The flow chart structure of the fuzzy logic coupled with the Taguchi method used in this study is shown in figure 15. Based on this figure, the optimization problem in this study is easily solved. It shows the procedure of the combined optimal method. At the beginning of the procedure, the given design variables are input force and rotary angle, and are assigned for an optimal process. If the results of optimal maximum stress are not satisfied by the yield strength of the proposed material, each of the input parameters with these levels will be divided again. If the optimal results are satisfied, the optimization process will be ended.

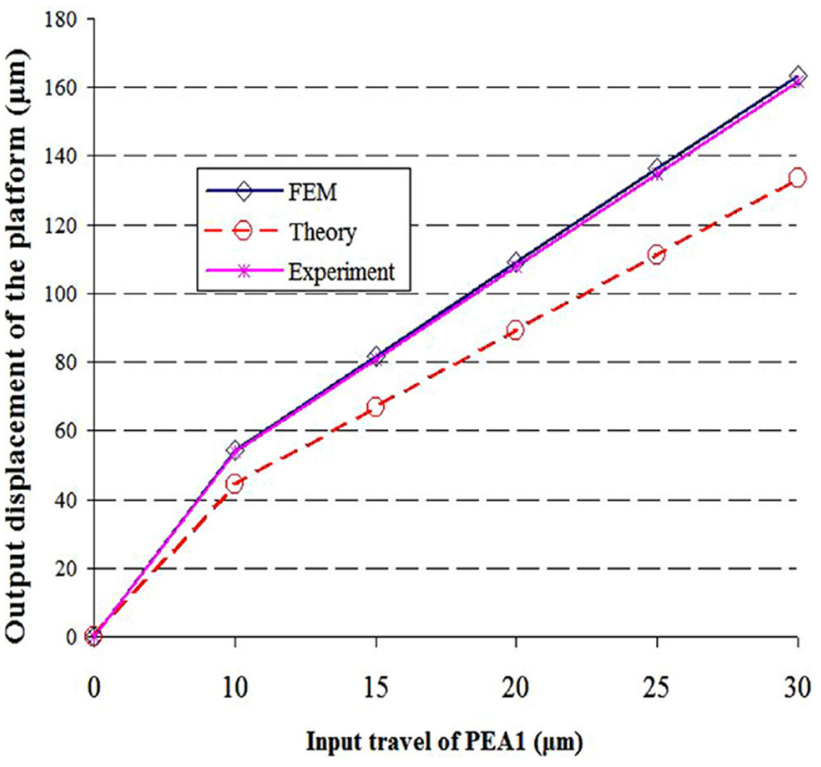

Figure 24. Comparison of travel amplification ratios obtained from FEM, theory and experiment.

\subsection{Results and discussion}

Three parameters: thickness $t_{1}$, thickness $t_{2}$ and length $b$, and their levels are presented in table 6 . The $L_{9}\left(3^{4}\right)$ OA was used for the experiment design, as presented in table 7 . It required only nine experiments instead of 27 full factorial experiments. The experimental results for nine samples, their $S / N$ ratios and MPI index are given in table 8 . These fuzzy rules are described in table 9.

This study used the two-input-one-output fuzzy logic system, as shown in figure 16 . The MFs of $S / N$ ratio of DI, $S / N$ ratio of FR and MPI are designed as shown in figures 17, 18 and 19, respectively. The mean of MPI at each level is calculated in table 10 . The optimal parameters are at $\mathrm{A} 1 \mathrm{~B} 3 \mathrm{C} 1$, as shown in figure 20 . The optimal results satisfied the constraints in Eqs. (10) and (11). The optimization process was thus ended here.

\section{Experimental tests}

\subsection{FEM validation}

Since the optimal level of design parameters was selected, the simulation and experimentation tests were conducted for the optimal parameters $\mathrm{A} 1 \mathrm{~B} 3 \mathrm{C} 1$ to verify the improvement of the performance characteristics. The first validations were performed by FEM in ANSYS 13 and compared to the outcome of the original design for A2B2C2 parameters. A load of $30 \mu \mathrm{m}$ of PEA1was applied to the platform along the $y$-axis, called the loaded case, in order to conduct this analysis.

The results indicated that the displacement was increased from 145.49 to $163.63 \mu \mathrm{m}$, corresponding to an 
improvement of $12.47 \%$, as shown in table 11 . The first mode of the natural frequency was increased from 653.95 to $871.53 \mathrm{~Hz}$, corresponding to an improvement of $33.27 \%$.

\subsection{Experimental validation}

The experimental equipment was installed on a vibrationisolated optical table (DAEIL systems, Model: DVIO-I1209M-100t, Korea) to avoid any unexpected vibrations.

6.2a Dynamic measurement: The measurements of the first natural frequency within the range of $50 \mathrm{~Hz}-1 \mathrm{kHz}$ were performed to evaluate the dynamic characteristics of the mechanism.

A modal hammer (Model 9722A2000-SN 2116555) from KISTLER was used to apply excitation to the mechanism, and the frequency response was measured using an accelerator (Type 8778A500M14, Model 4744892) from KISTLER. The accelerator was attached in such a way as to be opposite to the excitation from the modal hammer. A modal analyser (Model NI USB 9162) from National Instruments was used for data acquisition and analysis. A force sensor was attached to the end of the hammer to measure the applied force from the hammer. CUTPRO ${ }^{\circledR}$ software was installed on a computer to analyse the data, including the relationship between the first natural frequency and magnitude.

A photo of the experimental set-up is shown in figure 21 . The experiments were repeated five times. The first natural frequency was measured for the $y$-axis without PEA1, called the unloaded case. The first peak corresponds to the first natural frequency when the hammer excitation in the $y$ axis is $476 \mathrm{~Hz}$, as given in figure 22. Table 12 shows a comparison between the natural frequencies obtained by FEM and the experiments, with an error of $4.67 \%$. This indicated that the simulations are in good agreement with the experimental results.

6.2b Measurement of displacement: PEA1 (Model PSt 150/5/40 VS10) from the Piezomechanik GmbH was used. A high-speed bipolar amplifier (Model HAS 4011) from NF Corporation was used to drive the PEA1. Retro-reflective tape from ONO SOKKI Company was attached to the top of each thin aluminium beam; this aluminium leaf was then fixed onto the mobile platform. A preload was applied on PEA1. A laser vibrometer sensor (Model LV170) with a measurement range from $100 \mathrm{~nm}$ to $100 \mathrm{~mm}$, $1 \mathrm{~Hz}$ to $200 \mathrm{kHz}$ and reflective components from the ONO SOKKI Company was used to measure the displacement. A frequency response analyser (Model FRA 5097) from NF Corporation was used. A frequency response analyser (FRA) display software was installed on the computer. This FRA device can display the frequency and the displacement corresponding to individual electric voltages. Using the FRA display software, the data were displayed in diagrams. These are connected together to amplify electric voltage and display the displacement, frequency and phase.

Overall, experiments were repeated five times to obtain the average of the measured values. The experimental setup is shown in figure 23. Table 13 shows a comparison of the displacements from FEM and from the experiments, with an error of $1.21 \%$. As seen in figure 24 , the optimal parameters have a travel amplification ratio of 5.39, which is larger than the theoretical amplification ratio of 4.45 . The experimental results indicate that the actual amplification ratio of 5.39 is in good agreement with the FEM amplification ratio of 5.45 , with an error of $1.11 \%$. It can be concluded that the mechanism can achieve a large working travel amplification.

\section{Conclusions}

This paper presented a mechanical design and multiobjective optimization for a broad travel self-amplified 2-DOF monolithic mechanism. The proposed mechanism is capable of delivering motion in the $x$ - and $y$ direction.

Rectangular cross-section flexure hinges were utilized to achieve a large deflection. A double-lever mechanism was utilized to increase the travel/displacement amplification ratio of the mechanism. In addition, performance characteristics such as the displacement, the stress concentration, the first natural frequencies with PEA1 and without PEA1 and the amplification ratio were also investigated by FEA in ANSYS.

The effects of design parameters on the displacement and first natural frequency were determined by FEA based on the response surface methodology. The fuzzy-logic-based Taguchi method was then used to simultaneously optimize the displacement and the first natural frequency.

Finally, the validations by FEM showed that the displacement and the first natural frequency can be increased by up to $12.47 \%$ and $33.27 \%$, respectively, as compared with those of the original design. The experimental validations revealed that the experimental results are in good agreement with the simulations. This study also indicated that the developed fuzzy-logic-based Taguchi method is an effectively systematic reasoning approach for optimizing the multiple quality characteristics of flexure-based mechanisms.

The proposed 2-DOF monolithic mechanism is compact in size $(126 \mathrm{~mm}$ by $107 \mathrm{~mm})$, and is capable of broad travel because of its high travel amplification ratio. The results indicated that the working travel/displacement of the double-lever mechanism is much larger than that of traditional one-lever mechanism. It is expected to be widely applied in high-precision positioning systems and manipulations. 


\section{List of symbols}

$t_{1} \quad$ thickness of flexure hinge 1

$t_{2} \quad$ thickness of flexure hinge 2

$b$ distance from flexure hinge 1 to the point of PEA

$r_{a} \quad$ actual amplification ratio of lever type mechanism

$r_{t} \quad$ computed amplification ratio

$x_{o t}$ theoretical displacement of the platform along the $x$ axis

$y_{\text {ot }}$ theoretical displacement of the platform along the $y$ axis

$x_{o a} \quad$ real displacement of the platform along the $x$-axis

$y_{\text {oa }}$ real displacement of the platform along the $y$-axis

$\sigma_{\max }$ maximum equivalent stress

$M_{z} \quad$ axis movement

$K_{t} \quad$ stress concentration factor

$w \quad$ thickness of the proposed mechanism

$S / N \quad$ signal to noise

MPI multi-response performance index

DI maximum the displacement

FR maximum the first mode of natural frequency

SF safety factor

\section{Acknowledgements}

The authors acknowledge and thank the Ministry of Science and Technology of the Republic of China for their financial support of this study under Contract Number MOST 103-2221-E-151-035.

\section{References}

[1] Li Y and Xu Q 2009 Design and analysis of a totally decoupled flexure-based XY parallel micromanipulator. IEEE Trans. Robot. 25: 645-657

[2] Li Y and Xu Q2011 A novel piezoactuated XY stage with parallel, decoupled, and stacked flexure structure for micro-/nanopositioning. IEEE Trans. Ind. Electron. 58: 3601-3615

[3] Li Y, Huang J and Tang H 2012 A compliant parallel XY micromotion stage with complete kinematic decoupling. IEEE Trans. Autom. Sci. Eng. 9: 538-553
[4] Howell L L 2001 Compliant mechanisms. New York: Wiley

[5] Lai L, Gu G Y, Li P and Zhu L M 2011 Design of a decoupled 2-DOF translational parallel micro-positioning stage. In: Proceedings of the IEEE International Conference on Robotics and Automation, Shanghai International Conference Center, pp. 5070-5075

[6] Xiao S and Li Y 2013 Optimal design, fabrication and control of an XY micro-positioning stage driven by electromagnetic actuators. IEEE Trans. Ind. Electron. 60: 4613-4623

[7] Xu Q S 2014 Design and development of a compact flexurebased XY precision positioning system with centimeter range. IEEE Trans. Ind. Electron. 61(2): 893-903

[8] Philipp J T, Kimberly L T and Paul K H 2007 Design and modeling of a high-speed AFM-scanner. IEEE Trans. Control Syst. Technol. 15(5): 906-915

[9] Tang H and Li Y 2013 Design, analysis, and test of a novel 2-DOF nanopositioning system driven by dual mode. IEEE Trans. Robot. 29(3): 650-662

[10] Dao T P and Huang S C 2013 Design and analysis of compliant rotary joint. Appl. Mech. Mater. 372: 467-470

[11] Dao T P and Huang S C 2015a Robust design for a flexible bearing with 1-DOF translation using the Taguchi method and the utility concept. J. Mech. Sci. Technol. 29(8): 3309-3320

[12] Dao T P and Huang S C 2015b Design, fabrication, and predictive model of a 1-DOF translational, flexible bearing for high precision mechanism. Trans. Can. Soc. Mech. Eng. 39(3): 419-429

[13] ANSYS 2013 ANSYS workbench user's guide. Canonsburg, PA, USA: ANSYS

[14] Fnides B, Yallese M A, Mabrouki T and Rigal J F 2011 Application of response surface methodology for determining cutting force model in turning hardened AISI H11 hot work tool steel. Sadhana 36: 109-123

[15] Hari S and Pradeep K 2006 Optimizing feed force for turned parts through the Taguchi technique. Sadhana 31: 671-681

[16] Wierman M J 2008 Fuzzy sets. Fuzzy logic and control. In: An introduction to the mathematics of uncertainty. Omaha, Nebraska: Center of Mathematics of Uncertainty, Creighton University

[17] Klir G J and Yuan B 2005 Fuzzy sets and fuzzy logic: theory and applications, 3rd ed. New Delhi: Prentice Hall of India

[18] Mamdani E H and Assilian S 1975 An experiment in linguistic synthesis with a fuzzy logic controller. Int. J. ManMach. Stud. 7: 1-13 